Check for updates

Cite this: RSC Adv., 2018, 8, 11014

Received 22nd January 2018

Accepted 5th March 2018

DOI: $10.1039 / c 8 r a 00661 j$

rsc.li/rsc-advances

\section{Shape and structure controlling of calcium oxalate crystals by a combination of additives in the process of biomineralization $\uparrow$}

\author{
Nian Liu, ${ }^{\text {ab }}$ Hao Xie, (D) *ab Hang Ping, ${ }^{\mathrm{b}}$ Lin Wang, ${ }^{\mathrm{a}}$ Zewen Liu, ${ }^{\mathrm{ab}}$ Fei Tao, ${ }^{\text {ab }}$ Junhui Guo \\ and Bao-Lian Su*bc
}

The origin of complex hierarchical superstructures of biomaterials and their unique self-assembly mechanisms of formation are important in biological systems and have attracted considerable attention. In the present study, we investigated the morphological changes of calcium oxalate $\left(\mathrm{CaO}_{x}\right)$ crystals induced by additives including chiral aspartic acid, sodium citrate, $\mathrm{Mg}^{2+}$, casein and combinations of these molecules. The morphology and structure of $\mathrm{CaO}_{x}$ were identified with the use of various techniques. The morphogenesis of $\mathrm{CaO}_{x}$ crystals were significantly affected by chiral aspartic acid, sodium citrate or $\mathrm{Mg}^{2+}$. However, they only formed calcium oxalate monohydrate (COM). It was observed that the chiral aspartic acid, sodium citrate and casein adhered to the surface of the crystals. The adherence of $\mathrm{Mg}^{2+}$ to crystals was not evident. Casein significantly affected the formation of COM and calcium oxalate dihydrate (COD). The ratio of different $\mathrm{CaO}_{x}$ crystal forms is associated with the casein concentration. In combination with $\mathrm{Mg}^{2+}$ or citrate ions, casein showed improved formation of COD. The present study mimics biomineralization with a simple chemical approach and provides insight into the complicated system of $\mathrm{CaO}_{x}$ biomineralization as well as facilitates the understanding of urinary stone treatment.

\section{Introduction}

The increasing incidences and prevalence of stone disease is taking a toll on the social health system worldwide. ${ }^{1-4}$ The cause, the process of stone formation, and the different inhibitive mechanisms remain elusive..$^{5-7}$

$\mathrm{CaO}_{x}$ is the most frequently encountered crystalline phase in urethral calculi and renal calculi. ${ }^{3,8-10} \mathrm{CaO}_{x}$ is present in four crystalline types, namely, anhydrous (COA), ${ }^{\mathbf{1 1}} \mathrm{COM}, \mathrm{COD}$ and trihydrate $(\mathrm{COT})^{\mathbf{1 2}}$ and an amorphous type (ACO). ${ }^{\mathbf{1 3 , 1 4}}$ The major component of human urinary stones is COM, COD, or a mixture of the two species. ${ }^{15,16}$ Thermodynamically stable COM crystals with higher adsorptive capability and larger (101) surface area than those of COD crystals can easily come in contact with renal tubular cells. ${ }^{17}$

Understanding morphogenesis of COM facilitates the explanation of the mechanism of calculus formation and provides effective strategies for lithiasis diagnosis and

${ }^{a}$ School of Chemistry, Chemical Engineering and Life Sciences, Wuhan University of Technology, Wuhan, 430070, China. E-mail: h.xie@whut.edu.cn

${ }^{b}$ Laboratory of Living Materials at the State Key Laboratory of Advanced Technology for Materials Synthesis and Processing, Wuhan University of Technology, Wuhan, 430070, China.E-mail: bao-lian.su@unamur.be

'Laboratory of Inorganic Materials Chemistry, University of Namur, B-5000 Namur, Belgium

$\dagger$ Electronic supplementary information (ESI) available. See DOI: $10.1039 / \mathrm{c} 8 \mathrm{ra00661j}$ treatment. The controlled crystallization of $\mathrm{CaO}_{x}$ has been investigated in a variety of organic systems including Langmuir monolayers ${ }^{18}$ vesicles, ${ }^{19}$ micelles,${ }^{20}$ citrate, ${ }^{21-23}$ amino acids ${ }^{24}$ and natural macromolecules..$^{15,18,25-28}$ Some urinary proteins ${ }^{2}$ and polypeptides ${ }^{29}$ were observed to inhibit stone formation. These discoveries are significant for setting up effective therapies for stone disease, which have affected human beings for thousands of years ${ }^{6,30}$ and shed light on the complex structure formation of inorganic materials in an easier way. Due to the complicated functions and changeable activities of biological materials during the formation of inorganic materials, more research needs to be carried out on the shape and structure control of $\mathrm{CaO}_{x}$ crystals.

L-Aspartic acid is abundant in the human body and is frequently presents in the form of calculus. Some researchers believe that $\mathrm{L}$-aspartic acid plays a significant role in preventing $\mathrm{CaO}_{x}$ stone formation.,31,32 For example, Golovanova et al. observed that aspartic acid and glutamic acid inhibited the growth of $\mathrm{CaO}_{x}$ crystals. ${ }^{31}$ However, other researchers did not agree that L-aspartic acid has a significant role in affecting the $\mathrm{CaO}_{x}$ stone growth. Guo et al. found that aspartate and glutamate drastically reduced the aspect ratio during pit filling, but only weakly inhibited the crystal growth. ${ }^{15}$ The influence of $\mathrm{L}^{-}$ aspartic acid on $\mathrm{CaO}_{x}$ formation is ambiguous. Chirality is an important issue in crystallization. Many researchers have reported that different chiral materials have significant difference in their performances in vitro and in vivo. ${ }^{33}$ Therefore, the roles 
of both $\mathrm{L}^{-}$and $\mathrm{D}$-aspartic acid in $\mathrm{CaO}_{x}$ crystallization were investigated in the present study.

Sodium citrate ( $\mathrm{Na}_{3}$ Citrate) is a therapeutic agent of urinary stone disease. It has been used in clinical treatments for many years. ${ }^{34,35} \mathrm{Mg}^{2+}$ is abundantly available in nature as well as in the human body. It can decrease oxalate absorption in the gut, ${ }^{36}$ which in turn decreases the formation rate of $\mathrm{CaO}_{x}$. Since ions doped calcium oxalate crystals can be obtained by co-precipitation, ${ }^{37} \mathrm{Mg}^{2+}$ may also influence the property of crystallization of $\mathrm{CaO}_{x}$ in this manner. In the present study, the effects of these two chemicals on $\mathrm{CaO}_{x}$ crystallization were also investigated.

In the human body, macromolecules such as proteins may also affect the $\mathrm{CaO}_{x}$ crystallization. Casein is the major phosphate protein in bovine milk. It has brilliant $\mathrm{Ca}^{2+}$ binding property ${ }^{38}$ and contains numerous $\mathrm{L}$-aspartic residues. ${ }^{39}$ Higher concentration of both calcium ions and casein with stirring has been explored previously. ${ }^{39}$ However, lower concentration and non-stirring condition is beneficial to obtain the relationship between additives and the crystal forming process. ${ }^{33}$ Therefore, casein was employed as a macromolecular additive to study its influence on $\mathrm{CaO}_{x}$ crystallization.

The aim of this study was to investigate the crystallization of $\mathrm{CaO}_{x}$ under the influence of L-aspartic acid, D-aspartic acid, $\mathrm{Mg}^{2+}, \mathrm{Na}_{3}$ Citrate, and casein. Considering the complex environment in vivo, where different compositions co-exist, the effects of combinations of macromolecules and micro molecules on the $\mathrm{CaO}_{x}$ crystallization were studied. The morphology of $\mathrm{CaO}_{x}$ as well as polycrystalline superstructures had been identified by multiple techniques. The formation and complexity of hierarchical structures of $\mathrm{CaO}_{x}$ were evaluated. A possible self-assembly process of $\mathrm{CaO}_{x}$ was discussed. The present study suggests that it is possible to control the morphogenesis of $\mathrm{CaO}_{x}$ crystalline superstructures by a simple chemical method mimicking biomineralization.

\section{Experimental}

\section{Materials}

L-Aspartic acid (Bioxtra, $\geq 99 \%$, HPLC), D-aspartic acid (99\%), and Casein sodium salt from bovine milk were purchased from Sigma Aldrich. All other chemicals were of analytical grade, obtained commercially, and used without further purification. Ultra-pure water $(18.2 \mathrm{M} \Omega)$ was used for the preparation of aqueous solutions in all experiments.

\section{Synthetic procedures}

Fresh $2.5 \mathrm{mmol} \mathrm{L}^{-1}$ Tris-HCl buffer was used to prepare $2 \mathrm{mmol} \mathrm{L}^{-1} \mathrm{CaCl}_{2}$ and $2 \mathrm{mmol} \mathrm{L}^{-1} \mathrm{Na}_{2} \mathrm{C}_{2} \mathrm{O}_{4}$. All solutions were adjusted to $\mathrm{pH} 6$ at $37{ }^{\circ} \mathrm{C}$ by $\mathrm{HCl}$ or $\mathrm{NaOH}$ unless otherwise stated. $\mathrm{CaO}_{x}$ crystals were prepared by mixing equal volume of $\mathrm{CaCl}_{2}$ and $\mathrm{Na}_{2} \mathrm{C}_{2} \mathrm{O}_{4}$ solutions and incubating overnight at $37^{\circ} \mathrm{C}$. Appropriate amounts of additives were added into the $\mathrm{CaCl}_{2}$ solution before adjusting the $\mathrm{pH}$ if required. Then, the crystal products were collected by centrifugation (10000 $\mathrm{g}, 10$ minutes) or filtration through a $0.22 \mu \mathrm{m}$ nylon membrane and rinsed three times with Ultra-pure water. The crystals were then dried at $37^{\circ} \mathrm{C}$.

\section{Characterization techniques}

Scanning electron microscopy (SEM). Scanning electron microscopy (SEM) imaging was performed using a Hitachi $\mathrm{S}$ 4800 operating at acceleration voltages of $5 \mathrm{kV}$. All samples were coated with gold before test.

Powder X-ray diffraction (XRD). Powder X-ray diffraction (XRD) patterns of $\mathrm{CaO}_{x}$ were acquired using a Bruker AXS D8 Advance diffractometer with $\mathrm{Cu} \mathrm{K} \alpha(\lambda=1.5418 \AA)$ operating at $40 \mathrm{kV} / 40 \mathrm{~mA}$. Data were collected from $5^{\circ}$ to $80^{\circ}$ with a scanning rate of 0.05 degree per 0.5 second.

Thermogravimetric analyses (TGA). Thermogravimetric analyses (TGA) were carried out on a Setaram LABSYS Evo STA 1600. Samples were placed in $\mathrm{Al}_{2} \mathrm{O}_{3}$ crucibles without lid and were heated from room temperature to $1000^{\circ} \mathrm{C}$ at a heating rate of $5{ }^{\circ} \mathrm{C} \mathrm{min}{ }^{-1}$ under $20 \mathrm{~mL} \mathrm{~min}{ }^{-1}$ of air atmosphere.

Fourier transform infrared (FTIR). Fourier transform infrared (FTIR) spectra were recorded on a BRUKER VERTEX $80 \mathrm{~V}$. Samples were ground with potassium bromide $(\mathrm{KBr})$ and then made into a pellet. Data were collected in the range of 400 to $4000 \mathrm{~cm}^{-1}$, in which 64 scans were averaged at a resolution of $4 \mathrm{~cm}^{-1}$. Then, in the range of 1580 to $1720 \mathrm{~cm}^{-1}, 1024$ scans were averaged at a resolution of $4 \mathrm{~cm}^{-1}$, to show the difference at the Amide I area between samples and standards.

\section{Results and discussion}

\section{Influence of small molecular additives on mineralization of COM}

In the present study, the concentration of $\mathrm{Ca}^{2+}$ and $\mathrm{C}_{2} \mathrm{O}_{4}{ }^{2-}$ in crystallization assays was adjusted to $1 \mathrm{mmol} \mathrm{L}^{-1}$ to avoid fast precipitation of $\mathrm{CaO}_{x}$ and acquire sufficient amount of crystals for analysis. In a preliminary study, to optimise the concentration of additives, a broad range of concentrations were explored from $0.1 \mathrm{mmol} \mathrm{L}^{-1}$ to $2 \mathrm{mmol} \mathrm{L}^{-1}$ (Fig. S1-S4, see ESI $\dagger$ ). The results indicated that for additives $\mathrm{Mg}^{2+}$, $\mathrm{D}$-aspartic acid, and $\mathrm{L}^{-}$ aspartic acid, better crystal morphology can be viewed at $2 \mathrm{mmol} \mathrm{L}^{-1}$ of additive concentration. However, it was difficult to obtain crystals for $\mathrm{Na}_{3}$ Citrate at $2 \mathrm{mmol} \mathrm{L}^{-1}$ even on using centrifugation (10 $000 \mathrm{~g}, 10$ minutes) to collect crystals. Since the concentration of $\mathrm{Na}_{3}$ Citrate in healthy urine sample is around 1.1-1.6 mmol L, ${ }^{40-42}$ the additive concentration of $\mathrm{Na}_{3}$ Citrate was adjusted to $1 \mathrm{mmol} \mathrm{L}^{-1}$ for the rest of the study. Although effects of concentrated additives on crystallization may be more evident, it is rare in vivo. The addition of small molecular additives did not change the crystal form of COM (Fig. 1). Under these conditions, only COM was acquired in the presence or absence of additives. However, the addition of $\mathrm{Mg}^{2+}$ or $\mathrm{Na}_{3}$ Citrate drastically influenced the orientation of the crystals.

The orientation changes of crystals were also observed along with the pH changes from 4 to 7 (Fig. S5†). Upon the addition of $\mathrm{Mg}^{2+}$ or $\mathrm{Na}_{3}$ Citrate, larger (101) face of COM was observed as compared to those of other additives. In addition, relatively smaller (020) face and (121) face were observed in the presence of $\mathrm{Na}_{3}$ Citrate, resulting in the hexagon thin plate morphology of COM. The addition of chiral aspartic acid increased the size 


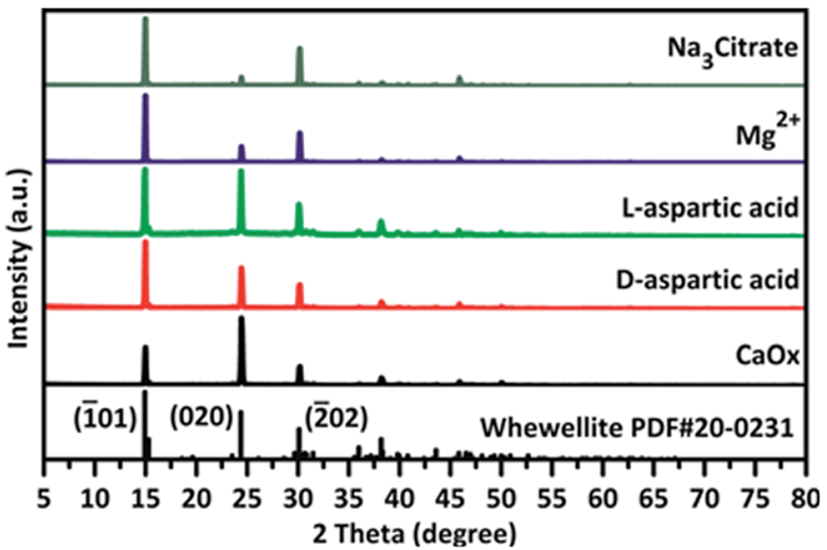

Fig. 1 XRD results of COM acquired with or without the presence of small molecular additives at $\mathrm{pH}$ 6. The additive concentration in solution was $2 \mathrm{mmol} \mathrm{L}^{-1}$ for chiral aspartic acid or $\mathrm{Mg}^{2+}$, and $1 \mathrm{mmol}$ $\mathrm{L}^{-1}$ for $\mathrm{Na}_{3}$ Citrate.

of COM and smoothed the edge. To prove the effects of aspartic acid on crystals, higher concentration of D-aspartic acid and $\mathrm{L}$-aspartic acid at $20 \mathrm{mmol} \mathrm{L}^{-1}$ were tested at both $\mathrm{pH} 6$ and $\mathrm{pH}$ 7 (Fig. 2). It was found that the size of the as-formed crystals were almost double in comparison with that formed in the absence of additives. However, the amounts of additives attached to the crystals were insufficient to be detected by TGA (Fig. S6, Table S1 $†$ ). In addition, there is evidence of interaction between $\mathrm{CaO}_{x}$ and these additives, particularly for $\mathrm{Na}_{3}$ Citrate, which is a strong bonding additive to $\mathrm{CaO}_{x}$ crystals (Fig. 1).

In most cases, the $\mathrm{pH}$ of human urine is around 6. Therefore, the $\mathrm{pH}$ was set to 6 in the present study to investigate the effect of additives as a function of crystallization time. $\mathrm{CaO}_{x}$ crystal formation is a rapid process. It only takes several minutes for the precipitation of $\mathrm{CaO}_{x}$ minerals after mixing calcium chloride solution with sodium oxalate solution at $37^{\circ} \mathrm{C}$. The resultant crystals were imperfect with a rough surface, rough edges and small fragments (Fig. S7 $\dagger$ ). However, there were differences

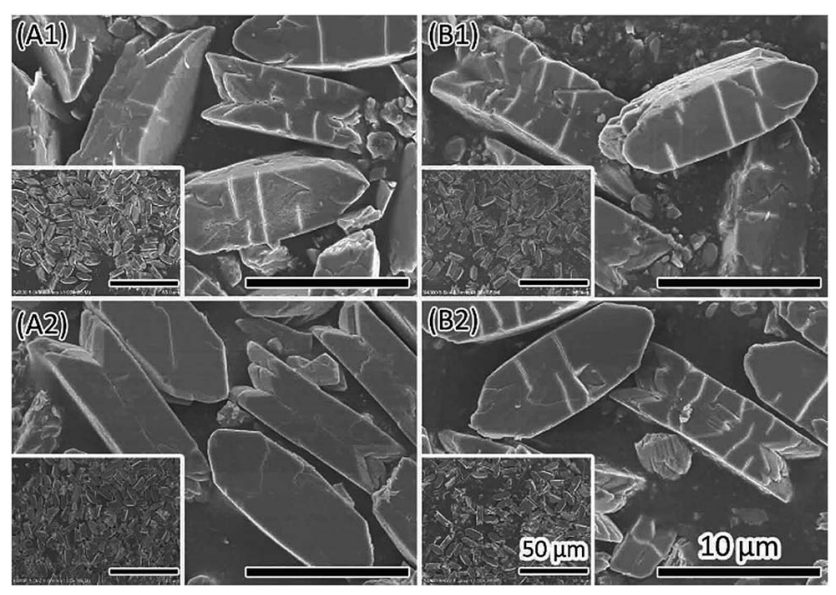

Fig. 2 SEM images of COM formed in the presence of $20 \mathrm{mmol} \mathrm{L}^{-1}$ of $\mathrm{D}$-aspartic acid (A1, A2) or L-aspartic acid (B1, B2). The $\mathrm{pH}$ solution was $\mathrm{pH} 6$ (A1, B1) and pH7 (A2, B2). between the effects of different additives. Chiral aspartic acid did not have significant influence on the crystals at this concentration. Both $\mathrm{Mg}^{2+}$ and $\mathrm{Na}_{3}$ Citrate can make the (101) face larger even in a short crystallization time. Additives might affect the crystal morphogenesis in two ways. One is that additives attached to the crystal face increased the stability by inactivating the dissolution and recrystallization process on this face. The other is that additives reduced the dissolution process by increasing the compete stress in solution.

Since there may be dissolution and recrystallization cycles, roles of additives were further studied in the ageing process of crystallization (Fig. 3). In a relatively long crystalline process without any additives, $\mathrm{CaO}_{x}$ crystals formed irregular shapes in 3 days. This is owing to the constant dissolution and recrystallization process with limited ion resources. In the presence of small molecular additives, most crystals retain their relatively complete (101) face. After 3 days, there were holes on the (020) face of crystals formed in chiral aspartic acid added solution. Some even changed to a sponge-like morphology in 10 days (Fig. S8†).

In combining this result with TGA (Fig. S6 and Table S1†) and energy dispersive spectrometry (EDS) (Fig. S9†), it is supposed that the binding of chiral aspartic acid to crystals is specific, which is coincident with the results reported by Grohe et $a .^{43}$ and $\mathrm{He}$ et al. ${ }^{24} \mathrm{Na}_{3}$ Citrate could function in the same manner, while $\mathrm{Mg}^{2+}$ functions in another. EDS analysis showed that $\mathrm{Mg}^{2+}$ was not present in $\mathrm{COM}$, although addition of $\mathrm{Mg}^{2+}$ did change the crystal shape. If $\mathrm{MgC}_{2} \mathrm{O}_{4} \cdot \mathrm{H}_{2} \mathrm{O}$ or $\mathrm{MgC}_{2} \mathrm{O}_{4} \cdot 2 \mathrm{H}_{2} \mathrm{O}$ were present, the TGA spectrum would confirm that the total weight loss was higher than that of pure COM. However, this did not occur as shown in Table S1. $\dagger$ Therefore, we concluded that there was no detectable $\mathrm{Mg}^{2+}$ in the formed crystals on addition of $2 \mathrm{mmol} \mathrm{L}^{-1} \mathrm{Mg}^{2+}$. This situation is quite different from $\mathrm{Fe}^{2+}$ doping in calcium oxalate. ${ }^{37}$

\section{Influence of casein on introducing dihydrate form of $\mathrm{CaO}_{x}$}

Macromolecules such as proteins can function as templates or catalysts in the biomineralization processes. Liu et al. reported the production of dumbbell-shaped $\mathrm{CaO}_{x}$ in the presence of amphiphilic phosphoproteins. ${ }^{25,39}$ They investigated effects of casein on the morphogenesis of $\mathrm{CaO}_{x}$ at $\mathrm{pH} 6.9$ at room temperature. However, this condition is different to that in vivo. In order to obtain insight of natural biomineralization, we explored the influence of casein on mineralization of $\mathrm{CaO}_{x}$ at pH 6 at $37^{\circ} \mathrm{C}$, which mimics the in vivo condition. Completely different morphology and crystal types were obtained in comparing with the previous study. ${ }^{25,39}$

Casein (ranging from $0.1 \mathrm{~g} \mathrm{~L}^{-1}$ to $4.0 \mathrm{~g} \mathrm{~L}^{-1}$ ) induced changes in the crystal morphology as well as crystal form (Fig. 4 and 5). Most of the crystals are fragments with a rough surface and branch inside (Fig. 4, A1 to F1). The crystal surface changed along with the addition of different amounts of casein (Fig. 4, A2 to F2), but not in a streak manner. The core region of the cross section was a bunch of branch-like crystals, elongating near the surface, which converted into particles (Fig. 4, A3 to F3).

XRD spectra (Fig. 5) showed that the intensity of the peaks belonging to COM decreased upon increasing casein 

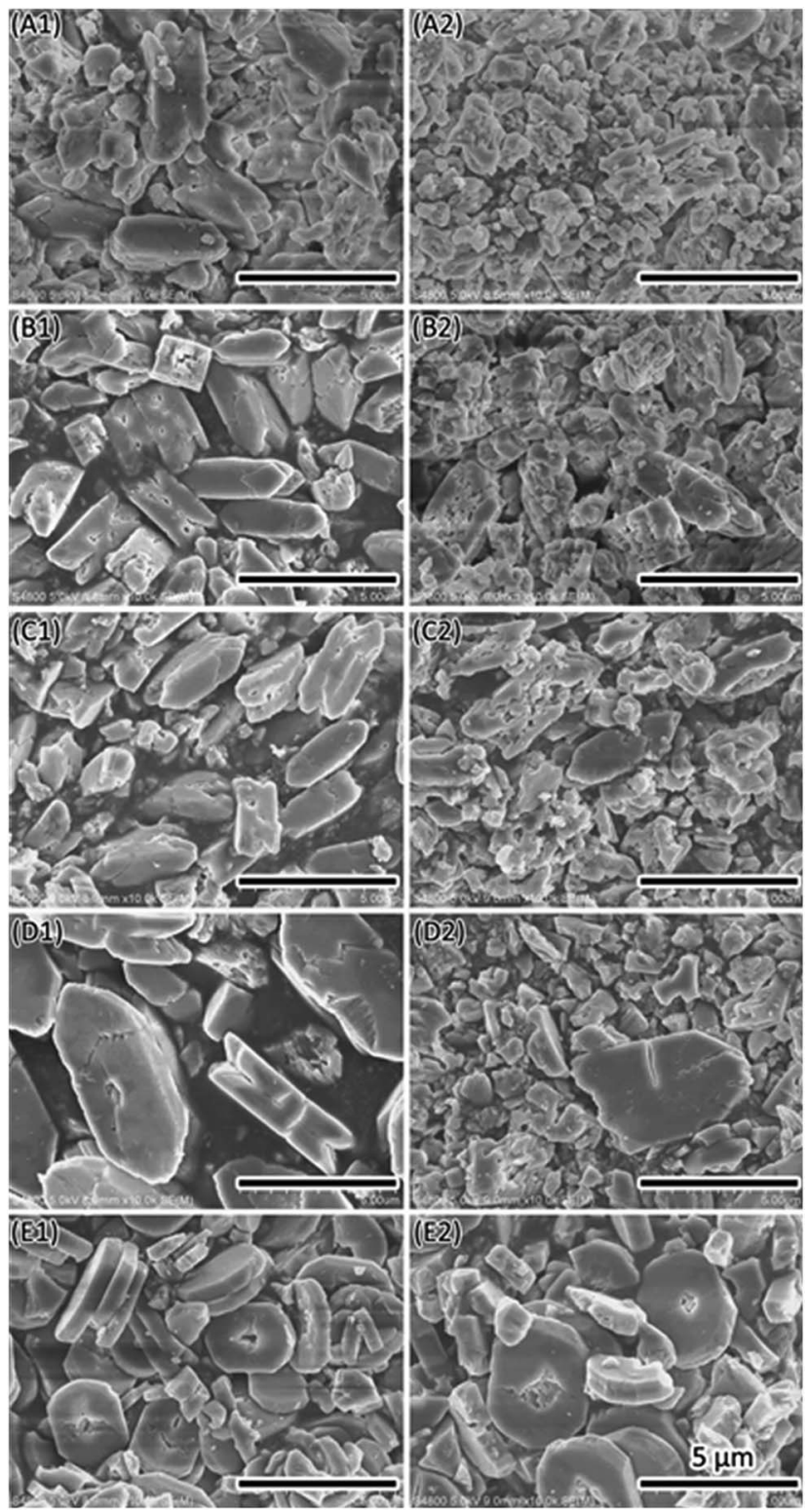

Fig. 3 SEM images show the change of $\mathrm{CaO}_{x}$ crystallization time form 0.5 day to 3 days. (A) $\mathrm{CaO}_{x}$ (B) $\mathrm{CaO}_{x}$ with $\mathrm{D}$-aspartic acid, (C) $\mathrm{CaO}_{x}$ with L-aspartic acid, (D) $\mathrm{CaO}_{x}$ with $\mathrm{Mg}^{2+}$, (E) $\mathrm{CaO}_{x}$ with $\mathrm{Na}_{3}$ Citrate. 1 to 2 refers to 0.5 day and 3 days, separately.

concentration, while intensity of COD peaks increased. This implied that more COD was formed along with involvement of more casein. Upon casein treatment, XRD peaks of $\mathrm{CaO}_{x}$ minerals were lower with wider full width at half maximum (FWHM) and uneven baselines. This implied the change of crystallinity or crystallographic texture. The change in XRD pattern might be due to the deposition of casein on the crystals and changes in the crystals structure. The impure crystals were fragile and readily broke during the treatment process, resulting in most crystals broken into small fragments.

Theoretically, the total weight loss of pure COM is $61.62 \%$, while this value is $65.83 \%$ for that of pure COD. Addition of casein induced formation of COD (as proven by XRD), which also affected the weight loss. When adding higher amount of

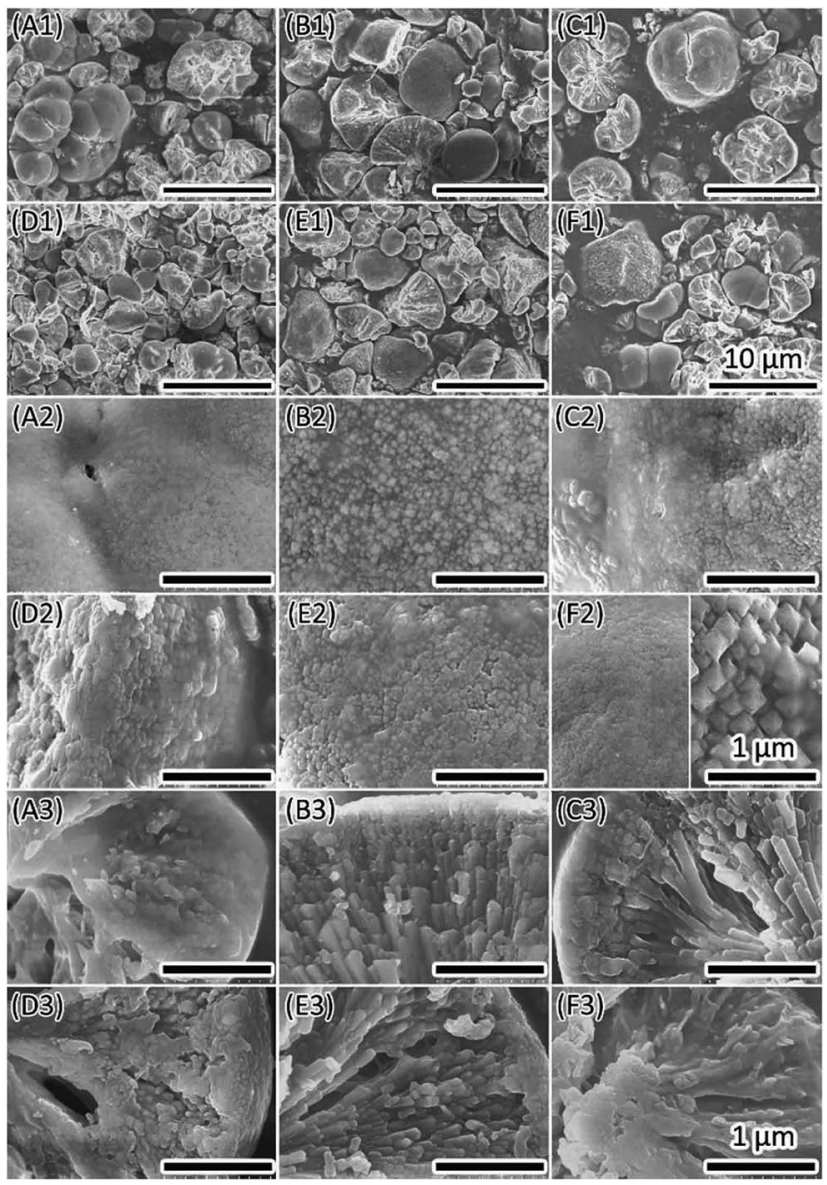

Fig. $4 \mathrm{CaO}_{x}$ formed within different concentration of casein in solution. (A) $0.1 \mathrm{~g} \mathrm{~L}^{-1}$, (B) $0.2 \mathrm{~g} \mathrm{~L}^{-1}$, (C) $0.4 \mathrm{~g} \mathrm{~L}^{-1}$, (D) $0.8 \mathrm{~g} \mathrm{~L}^{-1}$, (E) $2 \mathrm{~g} \mathrm{~L}^{-1}$, (F) $4 \mathrm{~g} \mathrm{~L}^{-1} .1$ is the overview, 2 is magnification of 1 to show the crystal surface, 3 is magnification of 1 also to show the cross section.

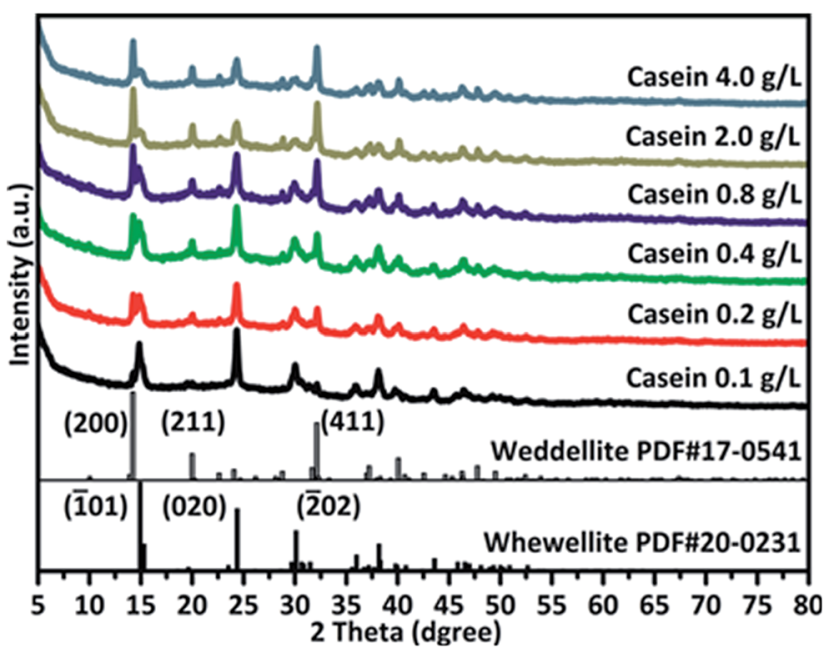

Fig. 5 XRD results illustrate changing from COM to COD formed with different concentration of casein. 
casein in solution (Table $\mathrm{S} 2 \dagger$ ), total weight loss was higher than $65.83 \%$, indicating that COD is not the only composition in the sample (can be proven by XRD). This implies that casein may contribute to the increase in weight loss.

\section{Influence of combinations of additives on $\mathrm{CaO}_{x}$ mineralization}

A living organism is a quite complex system, in which various molecules work together to maintain the essential biochemical and physiological processes. In a biomineralization process, the formation of biomineral requires functions from both macromolecules (mineral proteins) and small molecules (ions). In the present study, the effects of casein on $\mathrm{CaO}_{x}$ mineralization was further explored in the presence of $\mathrm{Mg}^{2+}$ or $\mathrm{Na}_{3}$ Citrate (Fig. 6). Small crystals were obtained with rough surface and different shapes.

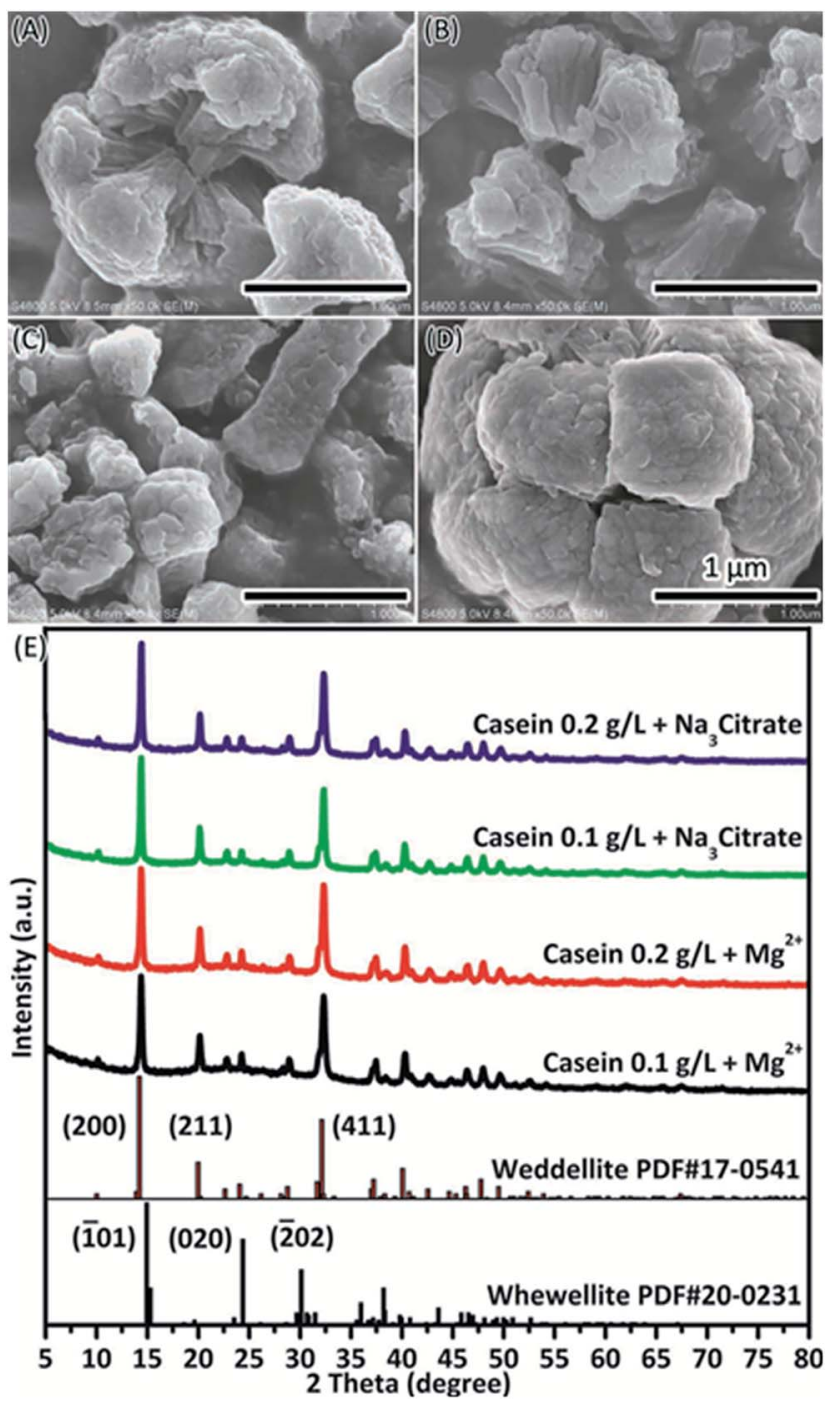

Fig. 6 COD formed with casein and small molecular additives. (A) $0.1 \mathrm{~g} \mathrm{~L}^{-1}$ casein $+2 \mathrm{mmol} \mathrm{L} \mathrm{Mg}^{2+}$, (B) $0.2 \mathrm{~g} \mathrm{~L}^{-1}$ casein $+2 \mathrm{mmol} \mathrm{L}^{-1}$ $\mathrm{Mg}^{2+}$, (C) $0.1 \mathrm{~g} \mathrm{~L}^{-1}$ casein $+1 \mathrm{mmol} \mathrm{L}{ }^{-1} \mathrm{Na}_{3}$ Citrate, (D) $0.2 \mathrm{~g} \mathrm{~L}^{-1}$ casein $+1 \mathrm{mmol} \mathrm{L}^{-1} \mathrm{Na}_{3}$ Citrate. (E) XRD spectra of COD formed with additives.
The involvement of casein in $\mathrm{CaO}_{x}$ mineralization in the presence of $\mathrm{Mg}^{2+}$ or $\mathrm{Na}_{3}$ Citrate was analysed by TGA. The amount of casein contained in the crystals increased on addition of $\mathrm{Mg}^{2+}$ (Table 1, Fig. S10 $)$. In this study, COM was acquired in the presence of $\mathrm{Mg}^{2+}$ (Fig. 1) and it did not significantly affect the TGA results (Fig. S6, Table S1 $\dagger$ ). When casein was included in the crystallization assay, it resulted in weight loss, which was much more significant if $\mathrm{Mg}^{2+}$ was also included (Table 1). The weight loss may be either due to the increase in amount of COD or due to the increase in amount of casein in the crystals. This is supported by the fact that weight loss of crystals formed in the presence of $0.2 \mathrm{~g} \mathrm{~L}^{-1}$ casein and $\mathrm{Mg}^{2+}$ is higher than that of pure COD and close to that formed in the presence of $0.8 \mathrm{~g} \mathrm{~L}^{-1}$ casein (Table S2 $\dagger$ ). However, the weight loss of the crystals formed in the presence of $0.1 \mathrm{~g} \mathrm{~L}^{-1}$ casein and $\mathrm{Mg}^{2+}$ is close to that of pure COD since COM may be included. We previously reported that addition of $\mathrm{Mg}^{2+}$ can increase the size of casein micelles. ${ }^{\mathbf{4 4}}$ The unique structure of casein micelles facilitates absorption of $\mathrm{Ca}^{2+}$ and subsequent interaction with the oxalate ions. Then, casein micelles form single small particles, which can function as the core of crystallization and assembly template. It allows fusion of small COD particles into branch-like structures of the resultant morphology. Since citrate can codeposit with crystals (Table S1 $\dagger$ ), weight change (Table 1) of crystals can be due to COD (Fig. 6) and co-deposited citrate (Table $\mathrm{S} 1 \dagger$ ). Citrate can attract more $\mathrm{Ca}^{2+}$ and increase the ratio of $\mathrm{Ca}^{2+} / \mathrm{C}_{2} \mathrm{O}_{4}{ }^{2-}$ around crystal, which functions with casein to induce COD formation. Significant depletion of water was observed at low temperature in the TGA for crystals in the presence of $\mathrm{Mg}^{2+}$ or $\mathrm{Na}_{3}$ Citrate. This may be due to the water in COD, which is weakly bonded in crystals than in $\mathrm{COM}^{45}$ or can be attributed to the interactions between deposited casein and water molecules.

The deposition of casein on $\mathrm{CaO}_{x}$ crystals were also analysed by XPS spectrometry (Fig. $7 \&$ Table 2). XPS results show the percentage of atoms in the crystal surface. It confirmed the presence of casein by increasing the amount of $\mathrm{N}$ atoms, which were present only in casein in this situation. The increasing amount of $\mathrm{C}$ was attributed to casein or $\mathrm{Na}_{3}$ Citrate. The peak of magnesium is not evident. This implies that the role of $\mathrm{Mg}^{2+}$ in solution is to upregulate the stress of bivalent cations and then decrease the dissolution process of $\mathrm{CaO}_{x}$.

Table 1 Weight loss (\%) of $\mathrm{CaO}_{x}$ and casein include samples

\begin{tabular}{|c|c|c|c|c|}
\hline Sample & $\begin{array}{l}{ }^{40-250} \\
{ }^{\circ} \mathrm{C}\end{array}$ & $\begin{array}{l}250-550 \\
{ }^{\circ} \mathrm{C}\end{array}$ & $\begin{array}{l}550-800 \\
{ }^{\circ} \mathrm{C}\end{array}$ & Total \\
\hline $\mathrm{CaO}_{x}$ & 14.5 & 18.4 & 27.3 & 60.2 \\
\hline Casein from Sigma & 14.7 & 60.8 & 17.3 & 92.8 \\
\hline Casein $4 \mathrm{~g} \mathrm{~L}^{-1}$ & 18.2 & 36.9 & 17.6 & 72.7 \\
\hline Casein $0.2 \mathrm{~g} \mathrm{~L}^{-1}+\mathrm{Mg}^{2+}$ & 25.8 & 24.1 & 19.5 & 69.4 \\
\hline Casein $0.2 \mathrm{~g} \mathrm{~L}^{-1}+\mathrm{Na}_{3}$ Citrate & 22.5 & 24.4 & 18.7 & 65.6 \\
\hline Casein $0.2 \mathrm{~g} \mathrm{~L}^{-1}$ & 16.7 & 27.5 & 20.3 & 64.5 \\
\hline Casein $0.1 \mathrm{~g} \mathrm{~L}^{-1}+\mathrm{Mg}^{2+}$ & 22.2 & 24.5 & 18.6 & 65.3 \\
\hline Casein $0.1 \mathrm{~g} \mathrm{~L}^{-1}+\mathrm{Na}_{3}$ Citrate & 21.6 & 23.6 & 18.0 & 63.2 \\
\hline Casein $0.1 \mathrm{~g} \mathrm{~L}^{-1}$ & 15.6 & 26.7 & 20.7 & 63.0 \\
\hline
\end{tabular}




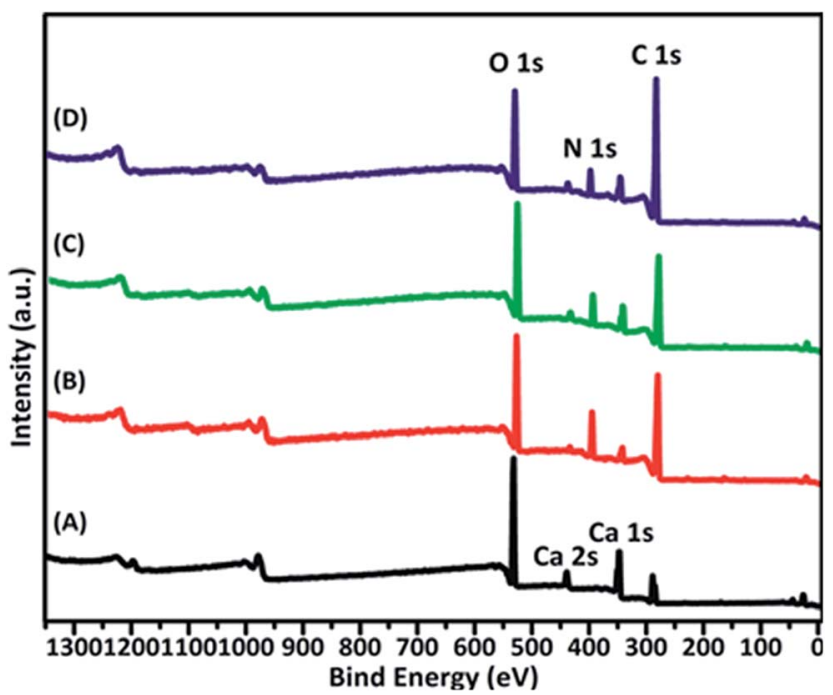

Fig. 7 XPS survey scan for $\mathrm{CaO}_{x}$ crystals formed within different additives in solution (A) $\mathrm{CaO}_{x}$, (B) $0.2 \mathrm{~g} \mathrm{~L}^{-1}$ casein, (C) $0.2 \mathrm{~g} \mathrm{~L}^{-1}$ casein + $2 \mathrm{mmol} \mathrm{L}{ }^{-1} \mathrm{Mg}^{2+}$, (D) $0.2 \mathrm{~g} \mathrm{~L}^{-1}$ casein $+1 \mathrm{mmol} \mathrm{L}{ }^{-1} \mathrm{Na}_{3}$ Citrate.

Table 2 Surface atomic percentage of casein included samples

\begin{tabular}{lcrrrr}
\hline Sample & C 1s & Ca 2p & N 1s & O 1s & Mg 1s \\
\hline $\mathrm{CaO}_{x}$ & 15.11 & 15.58 & 1.25 & 67.85 & 0.22 \\
Casein & 62.18 & 1.55 & 13.78 & 22.34 & 0.15 \\
Casein- $\mathrm{Mg}^{2+}$ & 61.81 & 3.33 & 10.21 & 24.52 & 0.13 \\
Casein- $\mathrm{Na}_{3}$ Citrate & 71.20 & 2.67 & 7.15 & 18.88 & 0.11
\end{tabular}

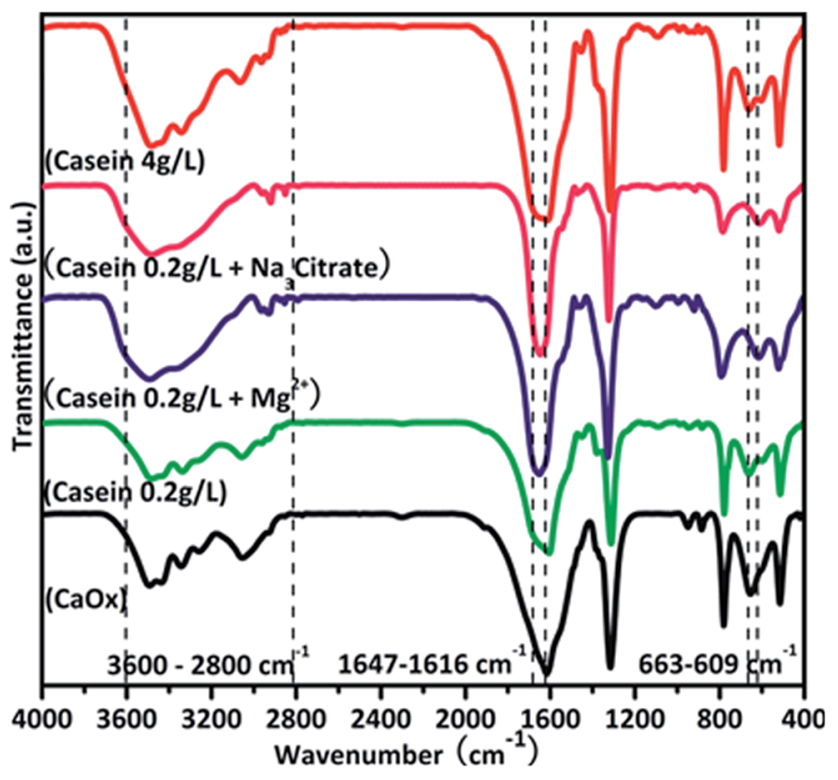

Fig. 8 FTIR results illustrate the influence of additives on $\mathrm{CaO}_{x}$.

The interaction between casein and minerals was analysed by FTIR (Fig. 8). The symmetrical stretching vibration and asymmetrical stretching vibration of $\mathrm{C}=\mathrm{O}$ bonds from oxalate were assigned to $1317 \mathrm{~cm}^{-1}$ and $1616 \mathrm{~cm}^{-1}$. The absorption
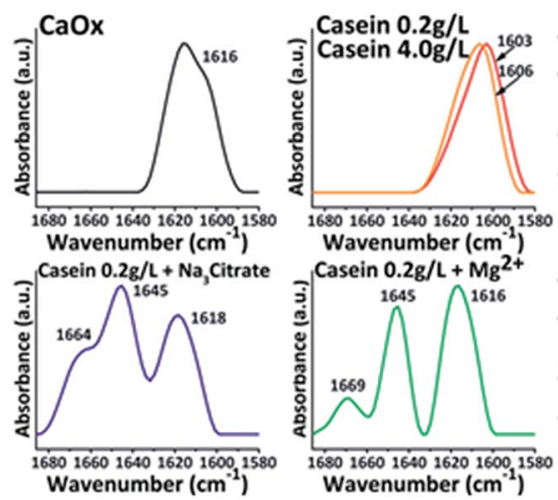

Wavenumber $\left(\mathrm{cm}^{-1}\right)$

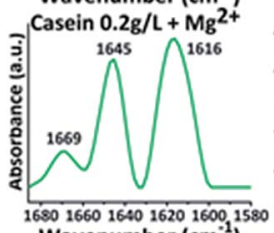

Wavenumber $\left(\mathrm{cm}^{-1}\right)$

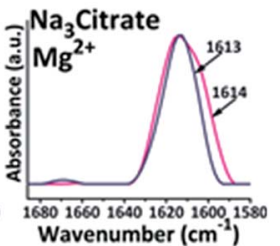

Wavenumber $\left(\mathrm{cm}^{-1}\right)$

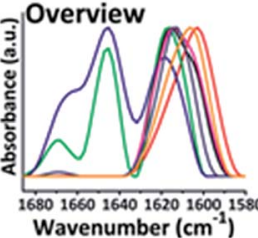

Fig. 9 FTIR results imply interactions between additives and $\mathrm{CaO}_{x}$.

bands in amide I region between $1600-1700 \mathrm{~cm}^{-1}$ corresponds to the secondary structure of the polypeptide backbone. ${ }^{38}$ This area was explored to obtain structural information of casein during the crystallization (Fig. 9). In the absence of casein, the acquired crystals only exhibit a characteristic peak of $\mathrm{CaO}_{x}$ around $1616 \mathrm{~cm}^{-1}$. Upon addition of casein without other additives, there was a red shift of the absorbance peak to $1616 \mathrm{~cm}^{-1}$. However, no characteristic peaks of proteins were observed in the spectrum. Upon addition of casein together with $\mathrm{Mg}^{2+}$ or $\mathrm{Na}_{3}$ Citrate, there were characteristic peaks at $1645 \mathrm{~cm}^{-1}$ and 1664 (1669) $\mathrm{cm}^{-1}$, which are related to the uncoiling and turning of the protein structure. Therefore, $\mathrm{Mg}^{2+}$ or $\mathrm{Na}_{3}$ Citrate might promote the interactions between casein and crystals.

\section{Conclusions}

In the present study, we explored the morphological and structural changes of $\mathrm{CaO}_{x}$ crystals induced by additives including chiral aspartic acid, sodium citrate, $\mathrm{Mg}^{2+}$, casein and a variety of combination of these molecules. The difference was not significant between L-aspartic acid and D-aspartic acid on affecting the COM formation. The adhesion of aspartic acid on $\mathrm{CaO}_{x}(\overline{101})$ face was proved by monitoring the ageing process of $\mathrm{CaO}_{x}$ mineralization. Casein could affect the morphogenesis of $\mathrm{CaO}_{x}$ minerals. However, its function was limited at low concentrations. Adherence of $\mathrm{Na}_{3}$ Citrate to the crystals was observed. It facilitated the $\mathrm{Ca}^{2+}$ ions to adhere around the crystals, which affected the morphogenesis and improved the COD formation in the presence of casein. $\mathrm{Mg}^{2+}$ regulated interactions between casein and $\mathrm{CaO}_{x}$ minerals through increasing casein micelle size, which subsequently improved the function of casein at low concentration. This observation is helpful for understanding molecular interactions and behaviours in vivo, for systems which are full of ions, proteins and other small or macro molecules. These molecules may function together in various physiological and biochemical processes as that of casein and other small molecules in biomineralization of $\mathrm{CaO}_{x}$. The present study helps us explore principles and mechanisms for the formation of crystalline superstructures as well as understand complex biomineralization in systems. 


\section{Conflicts of interest}

There are no conflicts to declare.

\section{Acknowledgements}

This work has been performed as part of the program for Changjiang Scholars and Innovative Research Team (IRT_15R52) of Chinese Ministry of Education. This work was also supported by the National Natural Science Foundation of China (31771032) and the Fundamental Research Funds for the Central Universities (WUT 2016IB006).

\section{Notes and references}

1 B. W. Turney, J. M. Reynard, J. G. Noble and S. R. Keoghane, BJU Int., 2012, 109, 1082-1087.

2 S. Narula, S. Tandon, S. K. Singh and C. Tandon, Life Sci., 2016, 164, 23-30.

3 Z. Zhao, Y. Xia, J. Xue and Q. Wu, Cryst. Growth Des., 2014, 14, 450-458.

4 S. A. Strope, J. S. Wolf and B. K. Hollenbeck, Urology, 2010, 75, 543-546.

5 H. Li, Q.-Z. Yao, Y.-Y. Wang, Y.-L. Li and G.-T. Zhou, Sci. Rep., 2015, 5, 7718.

6 A. P. Evan, E. M. Worcester, F. L. Coe, J. Williams and J. E. Lingeman, Urolithiasis, 2015, 43, 19-32.

7 D. E. Fleming, A. Van Riessen, M. C. Chauvet, P. K. Grover, B. Hunter, W. Van Bronswijk and R. L. Ryall, J. Bone Miner. Res., 2003, 18, 1282-1291.

8 Y. Shen, W. Yue, A. Xie, Z. Lin and F. Huang, Colloids Surf., A, 2004, 234, 35-41.

9 L. Maurice-Estepa, P. Levillain, B. Lacour and M. Daudon, Clin. Chim. Acta, 2000, 298, 1-11.

10 S. Wang, P. Du, N. Zhang, J. Liu, X. Tang, Q. Zhao and Y. Yang, Urolithiasis, 2016, 44, 203-210.

11 W. Zhao, N. Sharma, F. Jones, P. Raiteri, J. D. Gale and R. Demichelis, Cryst. Growth Des., 2016, 16, 5954-5965.

12 T. Lee and Y. C. Lin, Cryst. Growth Des., 2011, 11, 2973-2992.

13 S. Sun, D. Gebauer and H. Cölfen, Chem. Sci., 2017, 8, 14001405.

14 J. Ihli, Y.-W. Wang, B. Cantaert, Y.-Y. Kim, D. C. Green, P. H. H. Bomans, N. A. J. M. Sommerdijk and F. C. Meldrum, Chem. Mater., 2015, 27, 3999-4007.

15 S. Guo, M. D. Ward and J. A. Wesson, Langmuir, 2002, 18, 4284-4291.

16 A. Langdon and B. Grohe, Colloids Surf., B, 2016, 146, 296306.

17 J. Liu, H. Jiang and X.-Y. Liu, J. Phys. Chem. B, 2006, 110, 9085-9089.

18 S. R. Khan, P. A. Glenton and D. R. Talham, Kidney Int., 2002, 62, 2062-2072.

19 S. R. Khan, P. O. Whalen and P. A. Glenton, J. Cryst. Growth, 1993, 134, 211-218.

20 C. Zhong, Z. Deng, R. Wang and Y. Bai, Cryst. Growth Des., 2015, 15, 1602-1610.
21 L. J. Wang, W. Zhang, S. R. Qiu, W. J. Zachowicz, X. Y. Guan, R. K. Tang, J. R. Hoyer, J. J. De Yoreo and G. H. Nancollas, J. Cryst. Growth, 2006, 291, 160-165.

22 S. Qiu, A. Wierzbicki, C. Orme, A. Cody, J. Hoyer, G. Nancollas, S. Zepeda and J. De Yoreo, Proc. Natl. Acad. Sci. U. S. A., 2004, 101, 1811-1815.

23 M. L. Weaver, S. R. Qiu, J. R. Hoyer, W. H. Casey, G. H. Nancollas and J. J. De Yoreo, J. Cryst. Growth, 2007, 306, 135-145.

24 J. He, R. Lin, H. Long, Y. Liang and Y. Chen, J. Colloid Interface Sci., 2015, 454, 144-151.

25 Y. Liu, H. Mao, X. Liu, L. Qiao and R. Guo, CrystEngComm, 2014, 16, 8841-8851.

26 B. Grohe, A. Taller, P. L. Vincent, L. D. Tieu, K. A. Rogers, A. Heiss, E. S. Sorensen, S. Mittler, H. A. Goldberg and G. K. Hunter, Langmuir, 2009, 25, 11635-11646.

27 S. E. R. Hernandez and N. H. de Leeuw, Cryst. Growth Des., 2015, 15, 4438-4447.

28 T. Mandal, A. G. Shtukenberg, A. C. Yu, X. Zhong and M. D. Ward, Cryst. Growth Des., 2016, 16, 423-431.

29 K. R. Cho, E. A. Salter, J. J. De Yoreo, A. Wierzbicki, S. Elhadj, Y. Huang and S. R. Qiu, CrystEngComm, 2013, 15, 54-64.

30 M. López and B. Hoppe, Pediatr. Nephrol., 2008, 25, 49-59.

31 O. A. Golovanova, E. Y. Achkasova, Y. O. Punin and E. V. Zhelyaev, Crystallogr. Rep., 2006, 51, 348-354.

32 D. Škrtić and H. Füredi-Milhofer, J. Cryst. Growth, 1993, 129, 449-455.

33 W. G. Jiang, M. S. Pacella, D. Athanasiadou, V. Nelea, H. Vali, R. M. Hazen, J. J. Gray and M. D. McKee, Nat. Commun., 2017, 8, 1-13.

34 H. A. Fuselier, K. Moore, J. Lindberg, F. E. Husserl, F. E. Cole, D. J. Kok, D. Whitehead, D. J. Galliano and D. T. Erwin, Urology, 1998, 52, 988-994.

35 J. Dey, A. Creighton, J. S. Lindberg, H. A. Fuselier, D. J. Kok, F. E. Cole and L. L. Hamm, J. Urol., 2002, 167, 169-171.

36 R. P. Holmes, J. Knight and D. G. Assimos, Urolithiasis, 2016, 44, 27-32.

37 K. K. Gangu, S. Maddila, S. N. Maddila and S. B. Jonnalagadda, RSC Adv., 2017, 7, 423-432.

38 R. Gebhardt, N. Takeda, U. Kulozik and W. Doster, J. Phys. Chem. B, 2011, 115, 2349-2359.

39 Y. Liu, X. Liu, H. Mao and R. Guo, RSC Adv., 2015, 5, 8348683493.

40 R. Siener, A. Jahnen and A. Hesse, Eur. J. Clin. Nutr., 2004, 58, 270-276.

41 J. Dey, A. Creighton, J. S. Lindberg, H. A. Fuselier, D. J. Kok, F. E. Cole and L. L. Hamm, J. Urol., 2002, 167, 169-171.

42 H. A. Fuselier, K. Moore, J. Lindberg, F. E. Husserl, F. E. Cole, D. J. Kok, D. Whitehead, D. J. Galliano and D. T. Erwin, Urology, 1998, 52, 988-994.

43 B. Grohe, J. O'Young, D. A. Ionescu, G. Lajoie, K. A. Rogers, M. Karttunen, H. A. Goldberg and G. K. Hunter, J. Am. Chem. Soc., 2007, 129, 14946-14951.

44 A. Zhang, H. Xie, N. Liu, B.-L. Chen, H. Ping, Z.-Y. Fu and B.-L. Su, RSC Adv., 2016, 6, 110362-110366.

45 C. Conti, M. Casati, C. Colombo, M. Realini, L. Brambilla and G. Zerbi, Spectrochim. Acta, Part A, 2014, 128, 413-419. 